\title{
SISTEM INFORMASI DAN ADMINISTRASI RT (SIPAKRT) BERBASIS WEB
}

\author{
Andie $^{1)}$ \\ ${ }^{1}$ Fakultas Teknologi Informasi, Universitas Islam Kalimantan Muhammad Arsyad Al Banjari Banjarmasin \\ Email : andina777@gmail.com
}

\begin{abstract}
Abstrack
Sistem Informasi Pak RT (SIPAK RT) merupakan aplikasi yang akan dirancang dan dibuat untuk mempermudah pekerjaan Ketua Rukun Tetangga (RT), template dibuat berdasarkan surat yang dibutuhkan, warga bisa mengisi form pembuatan surat berdasarkan data dirinya dirumah, setelah data berhasil masuk Ketua RT akan mendapatkan pemberitahuan dan dapat segera memvalidasi data dan memprint surat langsung dan segera menandatanganinya. Apabila surat sudah selesai, akan ada pemberitahuan ke warga bahwa surat sudah dapat diambil. Aplikasi SIPAK RT berbasis online dan dapat digunakan dimana pun dan kapan pun. Masing-masing kepala keluarga akan mendapatkan Username dan password. Aplikasi juga dapat dibuka menggunakan berbagai device termasuk handphone warga masing-masing.
\end{abstract}

Keyword : sistem, informasi, rt, online, handphone.

\section{PENDAHULUAN}

Berdasarkan Peraturan Menteri Dalam Negeri Nomor 5 Tahun 2007 Tentang Pedoman Penataan Lembaga Kemasyarakatan yang berbunyi "Rukun Tetangga, untuk selanjutnya disingkat $R T$ atau sebutan lainnya adalah lembaga yang dibentuk melalui musyawarah masyarakat setempat dalam rangka pelayanan pemerintahan dan kemasyarakatan yang ditetapkan oleh Pemerintah Desa atau Lurah". Jadi salah satu tugas Ketua RT adalah melayani masyarakat dalam cakupan wilayahnya, salah satunya membantu pembuatan surat-menyurat. Pembuatan surat-menyurat biasanya menggunakan blangko atau template surat yang sudah di fotocopy. Warga harus mengisi buku tamu kemuadian mengisi data surat, Ketua RT kemudian mengetik surat berdasarkan data yang telah diberikan, setelah selesai baru menandatangani surat [2].

Sistem Informasi Pak RT (SIPAK RT) merupakan aplikasi yang akan dirancang dan dibuat untuk mempermudah semua pekerjaan diatas, template dibuat berdasarkan surat yang dibutuhkan, warga bisa mengisi form pembuatan surat berdasarkan data dirinya dirumah, setelah data berhasil masuk Ketua RT akan mendapatkan pemberitahuan dan dapat segera memvalidasi data dan memprint surat langsung dan segera menandatanganinya. Apabila surat sudah selesai, akan ada pemberitahuan ke warga bahwa surat sudah dapat diambil.
Aplikasi SIPAK RT berbasis online dan dapat digunakan dimana pun dan kapan pun. Masing-masing kepala keluarga akan mendapatkan Username dan password. Aplikasi juga dapat dibuka menggunakan berbagai device termasuk handphone warga masing-masing.

\section{METODE PENELITIAN}

\section{Objek Penelitian}

Objek penelitian ini dilakukan di RT. 27 Kelurahan Sei Miai Kecamatan Banjarmasin Utara, Banjarmasin, Kalimantan Selatan.

\section{Metode Pengumpulan Data}

Penelitian dilaksanakan dengan mengacu pada sistem development life cycle (SDLC) yaitu dengan melakukan perencanaan, analisa, desain dan implementasi. Pada tahap perencanaan dilakukan pengumpulan data ke obyek penelitian yaitu dengan melakukan wawancara pada pengurus RT/RW untuk mengetahui sistem yang sedang berjalan, selain itu juga dilakukan pengumpulan data terkait dengan pelayanan yang dilakukan serta dokumen pendukung lainnya seperti prosedur pelayanan, form pelayanan dan lain-lain [1].

Berdasarkan hasil pengumpulan data dilakukan penetapan ruang lingkup pembahasan, yaitu lebih menitikberatkan pada komunikasi antara pengurus RT dengan warganya, terkait dengan penyampaian 
pengumuman atau berita pada warga, pengajuan surat permohonan warga, penyampaian aspirasi warga pada pengurus dalam bentuk kritik maupun saran, komplain maupun informasi dari warga serta penyampaian laporan keuangan.

Hasil pengumpulan data akan diolah untuk dilakukan analisa permasalahan dengan menentukan masalah yang timbul beserta dampaknya dan selanjutnya dapat diketahui apa yang dibutuhkan untuk menangani masalah yang timbul. Hasil analisa akan menjadi landasan dalam melakukan perancangan sistem yang nantinya diharapkan dapat mengatasi permasalahan yang timbul. Tahap terakhir yang dilakukan adalah mengimplementasikan desain yang telah dibuat dan melakkukan uji coba terhadap sistem yang telah terbentuk.

Tahap-Tahap Pembuatan Sistem

Dalam pengembangan sistem ini, ada beberapa tahapan yang harus dilakukan. Adapun tahapan tersebut adalah sebagai berikut:

\section{Analisa Sistem}

Dalam membangun aplikasi ini diperlukan perencanaan yang baik agar dihasilkan sistem yang dapat berjalan optimal. Tahap perencanaan ini terbagi atas 2 yaitu [3]:

a. Menentukan tujuan pembuatan aplikasi

Tujuan penelitian ini adalah agar memberikan kemudahan dalam pembuatan surat-menyurut pada Ketua RT.

b. Menentukan siapa yang akan menjadi pemakai

Aplikasi digunakan oleh Ketua RT dan Warganya.

2. Perancangan Sistem

Proses perancangan yang baik diperlukan untuk pembuatan sistem informasi secara terperinci, dilakukan dengan cara:

a. Rancangan Menu

Aplikasi terbagi menjadi 2 (dua)

halaman utama yaitu halaman User

(Warga) dan Admin (Ketua RT).

Berikut rancangan menu yang

terbentuk dari aplikasi:
Tabel 3.1. Rancangan Menu

\begin{tabular}{|c|c|c|}
\hline No & Halaman & Menu \\
\hline 1 & \multirow{7}{*}{ User/Warga } & Home \\
\hline 2 & & Warga \\
\hline 3 & & Layanan \\
\hline 4 & & Pengumuman \\
\hline 5 & & Pengaduan \\
\hline 6 & & Keuangan \\
\hline 7 & & Logout \\
\hline 1 & \multirow{8}{*}{$\begin{array}{l}\text { Admin/Ketua } \\
\text { RT }\end{array}$} & Home \\
\hline 2 & & Warga \\
\hline 3 & & Layanan \\
\hline 4 & & Pengumuman \\
\hline 5 & & Pengaduan \\
\hline 6 & & Keuangan \\
\hline 7 & & Admin \\
\hline 8 & & Logout \\
\hline
\end{tabular}

b. Rancangan Database

Pada aplikasi ini terdapat satu buah database diberi nama "sipakrt" dan memiliki 7 (tujuh) tabel di dalamnya. Berikut rancangan database yang terbentuk.

Tabel 3.2. Tabel Admin

\begin{tabular}{|lll|}
\hline Field & Type & Ket \\
id & int(11) & $\begin{array}{l}\text { Primary \& Auto } \\
\text { Increamen }\end{array}$ \\
\hline nama & varchar(200) \\
\hline Username & varchar(50) \\
\hline password & varchar(100) \\
\hline
\end{tabular}

Tabel 3.3. Tabel warga

\begin{tabular}{|c|c|c|}
\hline Field & Type & Ket \\
\hline id & $\operatorname{int}(11)$ & $\begin{array}{l}\text { Primary \& } \\
\text { Auto } \\
\text { Increamen }\end{array}$ \\
\hline nm_warga & $\operatorname{varchar}(200)$ & \\
\hline nkk & bigint(16) & \\
\hline nik & bigint(16) & \\
\hline tmp_lahir & $\operatorname{varchar}(100)$ & \\
\hline tgl_lahir & $\operatorname{varchar}(10)$ & \\
\hline jk & varchar(10) & \\
\hline gol_darah & $\operatorname{varchar}(5)$ & Null \\
\hline alamat & text & \\
\hline rt & $\operatorname{int}(11)$ & \\
\hline rw & $\operatorname{int}(11)$ & Null \\
\hline kel & $\operatorname{varchar}(100)$ & Null \\
\hline
\end{tabular}




\begin{tabular}{|lll|}
\hline kec & varchar(100) & Null \\
\hline agama & varchar(20) & \\
\hline status_kwn & varchar(12) \\
\hline pekerjaan & varchar(100) & Null \\
\hline $\begin{array}{l}\text { kewarganeg } \\
\text { araan }\end{array}$ & varchar(3) \\
\hline telp_wa & varchar(15) \\
\hline email & varchar(100) \\
\hline password & varchar(100) \\
\hline status & varchar(20) \\
\hline
\end{tabular}

Tabel 3.7. Tabel keuangan_masuk

\begin{tabular}{|lll|}
\hline id & int(11) & $\begin{array}{l}\text { Ket } \\
\text { Increamen \& Auto }\end{array}$ \\
\hline tgl & varchar(10) & \\
\hline ket & text & \\
\hline jumlah & bigint(20) & \\
\hline id_Admin & int(11) & \\
\hline
\end{tabular}

Tabel 3.4. Tabel layanan

\begin{tabular}{|lll|}
\hline id & $\begin{array}{l}\text { Type } \\
\text { int(11) }\end{array}$ & $\begin{array}{l}\text { Ket } \\
\text { Primary \& } \\
\text { Anto } \\
\text { Increamen }\end{array}$ \\
\hline id_warga & int(11) & \\
\hline nm_warga & varchar(200) \\
\hline keperluan & text \\
\hline keterangan & text \\
\hline tgl_pengajuan & varchar(10) \\
\hline status & varchar(20) \\
\hline catatan_rt & text \\
\hline
\end{tabular}

Tabel 3.8. Tabel keuangan_keluar

\begin{tabular}{|lll|}
\hline Field & Type & Ket \\
\hline id & int(11) & $\begin{array}{l}\text { Primary \& Auto } \\
\text { Increamen }\end{array}$ \\
\hline tgl & varchar(10) \\
\hline ket & text \\
\hline jumlah & bigint(20) \\
\hline id_Admin & int(11) \\
\hline
\end{tabular}

c. Relasi Antar Tabel

Berikut relasi antar tabel yang dibuat:

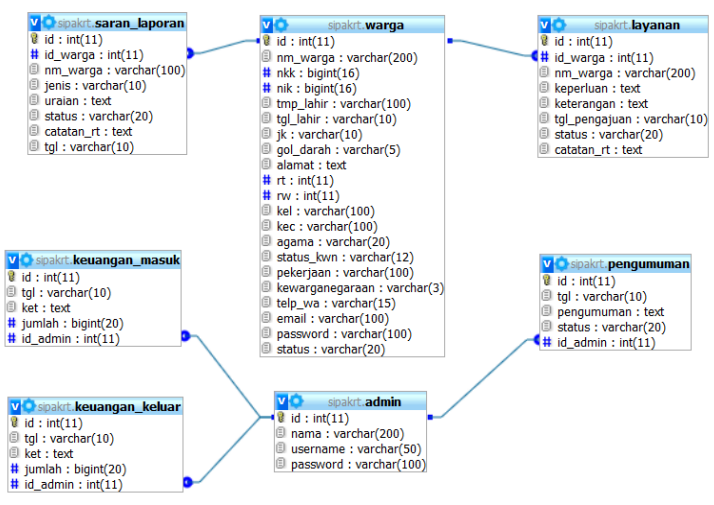

Gambar 3.1. Relasi Antar Tabel

Tabel 3.6. Tabel saran_laporan

\begin{tabular}{|lll|}
\hline id & $\begin{array}{l}\text { Type } \\
\text { int(11) }\end{array}$ & $\begin{array}{l}\text { Pet } \\
\text { Increamen \& Auto }\end{array}$ \\
\hline id_warga & int(11) & \\
\hline nm_warga & varchar(100) & \\
\hline jenis & varchar(10) & \\
\hline uraian & text & \\
\hline status & varchar(20) & \\
\hline catatan_rt & text & Null \\
\hline tgl & varchar(10) & \\
\hline
\end{tabular}


d. Diagram Konteks

Berikut Diagram Kontek yang

terbentuk:

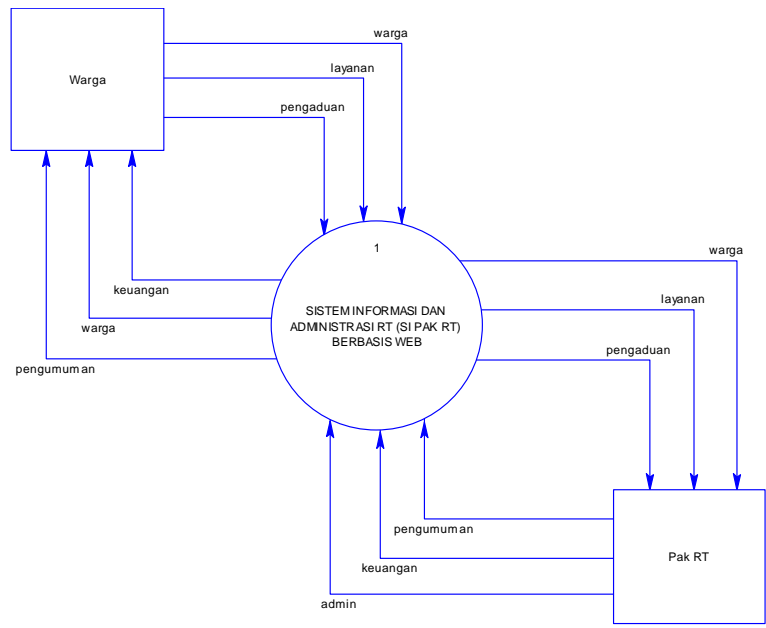

Gambar 3.2. Diagram Konteks

e. Data Flow Diagram (DFD)

Berikut Data Flow Diagram (DFD) yang terbentuk:

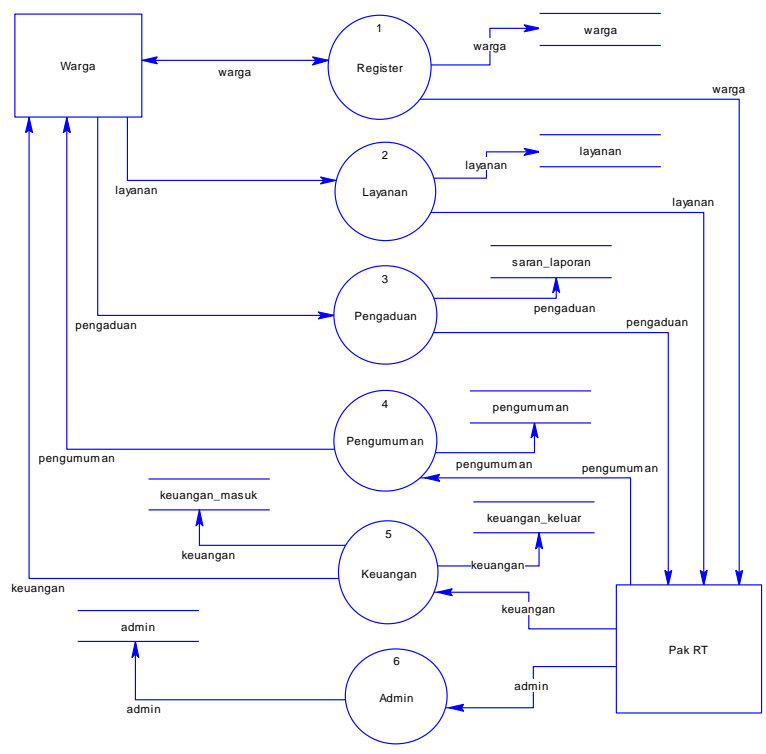

Gambar 3.3. Data Flow Diagram (DFD)

f. Rancangan Template Layout Tampilan

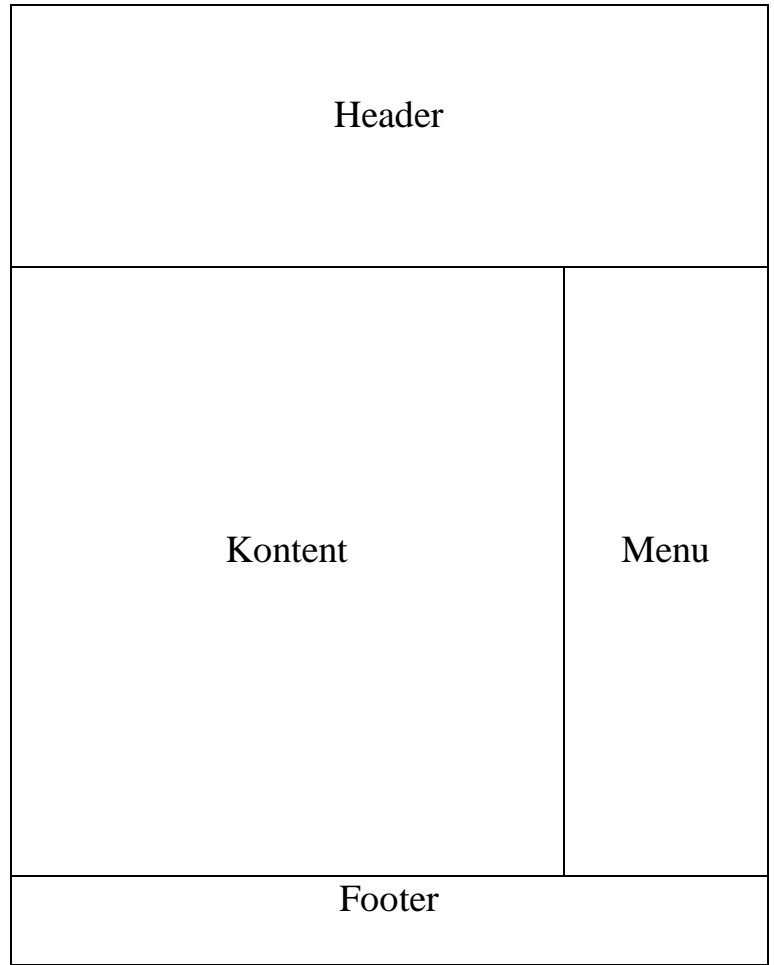

Gambar 3.4. Rancangan template layout tampilan

g. Pembuatan Program Pembuatan aplikasi ini dibuat menggunakan bahasa pemrograman $P H P$ dan $M y S Q L$ sebagai pengelola databasenya.

3. Testing Aplikasi

Pada tahap ini, dilakukan uji terhadap sistem yang telah selesai dibuat dengan menggunakan modem dan satu buah laptop server, setiap proses pendataan dilakukan langsung pada hosting dan domain yang telah disediakan sebelumnya.

\section{HASIL DAN PEMBAHASAN}

\section{Implementasi Sistem}

Sistem Informasi dan Administrasi RT (SiPak RT) terdiri dari 2 (dua) halaman utama yaitu halaman Warga (User) dan halaman Pak RT (Admin), setiap halaman memiliki menu 
yang berbeda. Berikut tampilan masing-masing halaman.

1. Halaman Login

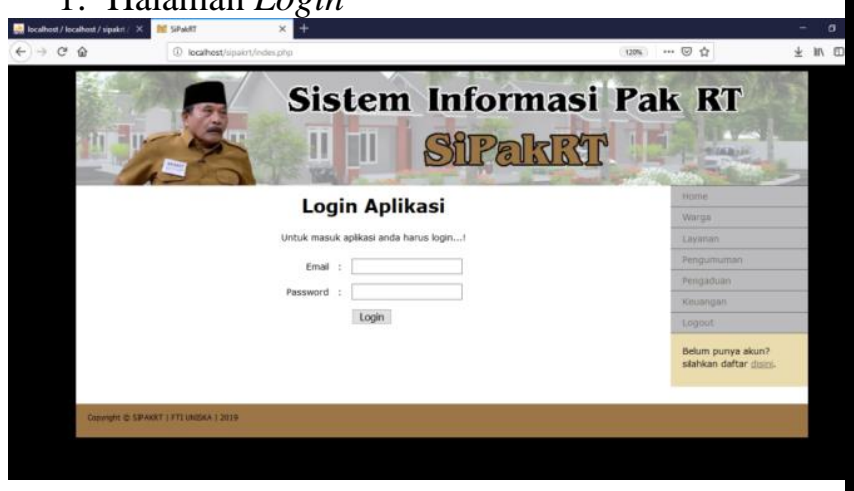

Gambar 4.1. Halaman Login

2. Halaman Register

Gambar 4.3. Halaman Home

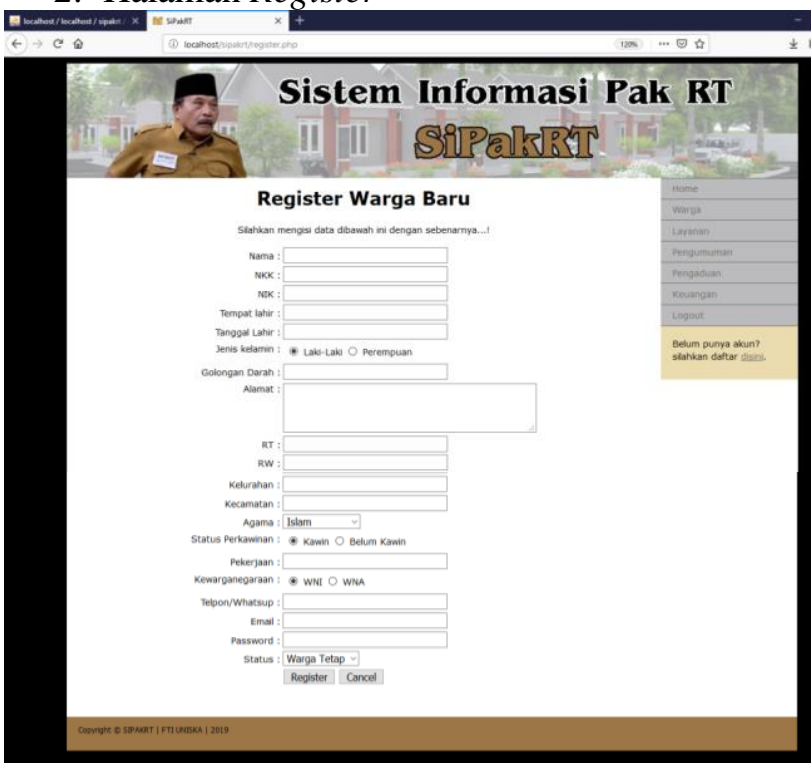

Gambar 4.2. Halaman Register

4. Halaman Warga

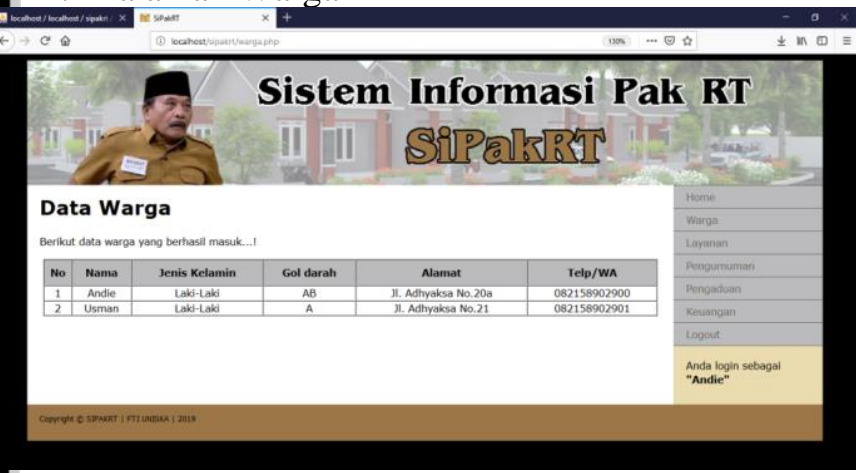

Gambar 4.4. Halaman Warga

5. Halaman Layanan

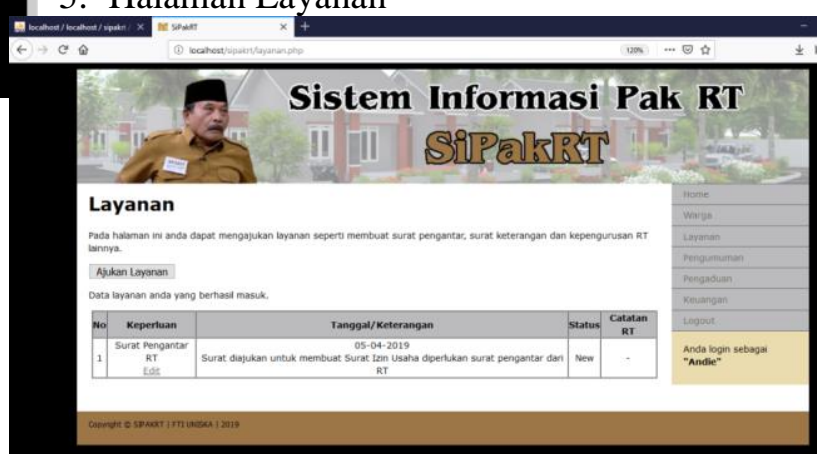

Gambar 4.5. Halaman Layanan 
dibuat, kemudian juga dilakukan testing edit

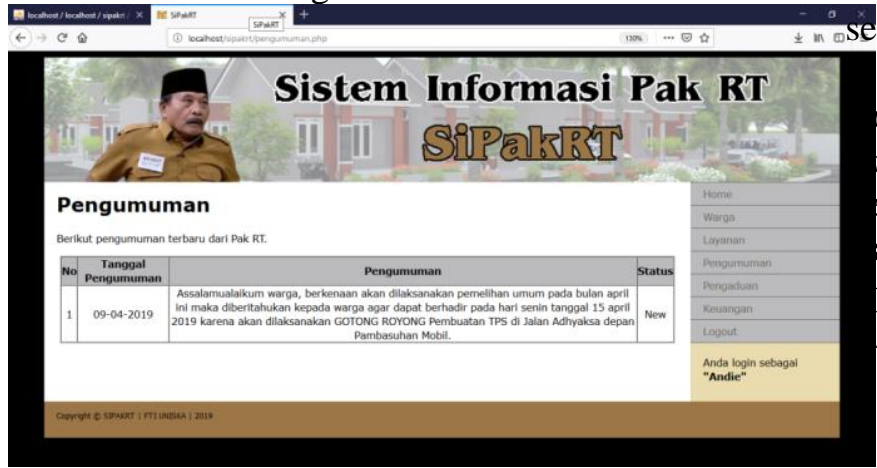

tiap data dan juga hapus data. Setelah aplikasi rasa sudah berjalan dengan baik maka likasi diuji coba dengan mengupload ke line melalui hosting percobaan, dilakukan rcobaan mengakses dengan sample 2 orang arga dan 1 orang ketua RT. Hasilnya setiap put data dilakukan cukup mudah dan serfriendly.

Gambar 4.6. Halaman Pengumuman

7. Halaman Pengaduan

\section{KESIMPULAN}

Berdasarkan hasil penelitian yang telah lakukan, sistem yang dibangun telah dapat

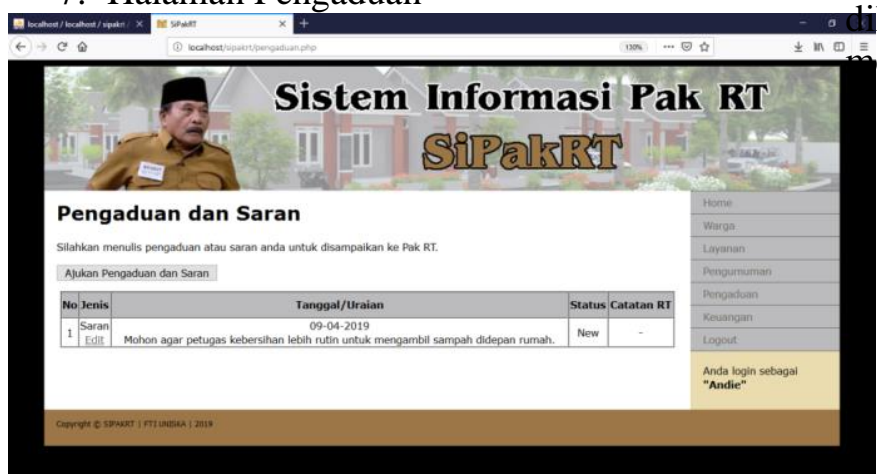

Gambar 4.7. Halaman Pengaduan

8. Halaman Keuangan

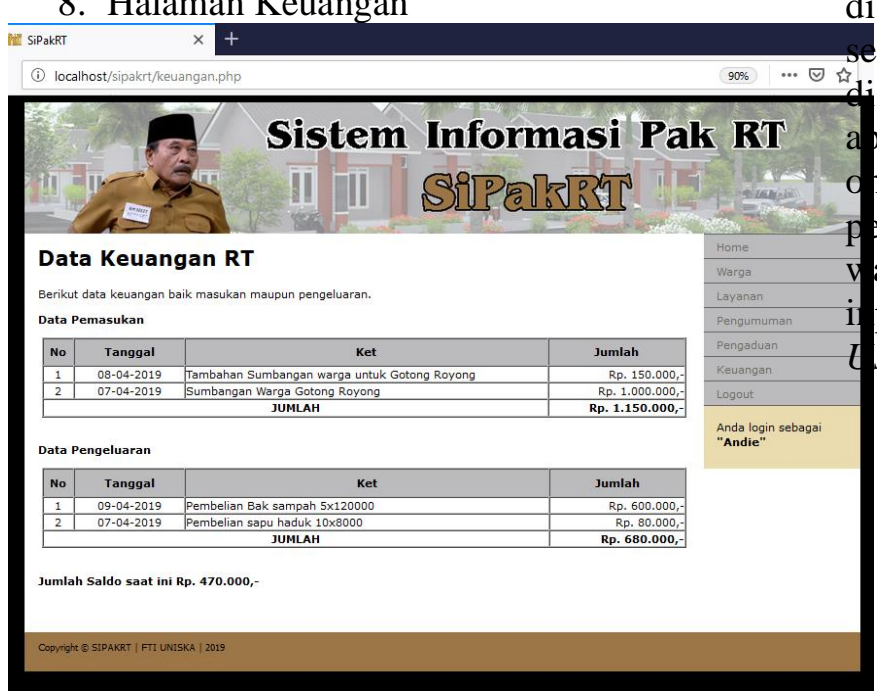

Gambar 4.8. Halaman Keuangan

\section{Testing Aplikasi}

Testing aplikasi awalnya dilakukan menggunakan localhost yaitu dengan cara menginput satu persatu setiap form yang telah
1. Mempermudah dalam pembuatan suratmenyurat RT

2. Mempermudah dalam pembuatan buku tamu RT

3. Mempermudah perekapan data RT

4. Mempermudah urusan warga ke Ketua RT

5. Mempercepat proses pembuatan suratmenyurat RT menggunakan localhost yaitu dengan cara menginput satu persatu setiap form yang telah dibuat, kemudian juga dilakukan teting edit tiap data dan juga hapus data. Setelah aplikasi rasa sudah berjalan dengan baik maka likasi diuji coba dengan mengupload ke line melalui hosting percobaan, dilakukan rcobaan mengakses dengan sample 2 orang arga dan 1 orang ketua RT. Hasilnya setiap put data dilakukan cukup mudah dan serfriendly.
Testing aplikasi awalnya dilakukan 


\section{REFERENSI}

[1] A. and S. Widodo, "Sistem Informasi RT/RW Sebagai Media Komunikasi Warga Berbasis Web," Smatika Jurnal, p. Volume 4 Edisi 1, 2014.

[2] W. Sumadiono, Buku Pedoman Umum Organisasi dan Administrasi Rukun Warga Rukun Tetangga, Yogyakarta: CV. Budi Utama, 2018.

[3] D. Retnosari, M. R. Wathani and A. , "Sistem Informasi E-Learning Untuk Pengembangan Media Pembelajaran Pada Madrasah Aliyah," Info-Teknik, vol. 2, pp. 191-200, 2018.

[1] M. Rasyidan, A. and M. I. Firdaus, "Perancangan Aplikasi Absensi Kelas Berbasis SMS Gateway," Al Ulum Jurnal Sains dan Teknologi, vol. 2, no. 2477-4731, pp. 52-57, 2016.

[2] A. S. Sitanggang and A. W. Sutardi, "Sistem Informasi Penyewaan Rental Mobil di CV. Surya Rental Mobil Bandung," JATI : Jurnal Teknologi dan Informasi UNIKOM, vol. 1, no. 2088-2270, p. 5, 2014.

[3] D. C. Mahendra, T. Susyanto and S. Siswanti, "Sistem Monitoring Mobil Rental Menggunakan GPS Tracker," Jurnal Ilmiah SINUS, vol. 16, no. 1693-1173, p. 2, 2018.

[4] M. H. Nuri, "Sistem Informasi Manajemen Rental Mobil Berbasis Web," Program Studi Teknik Informatika Fakultas Sains dan Teknologi UIN Sunan Kalijaga, Yogyakarta, 2014. 